\title{
A PHARMACOLOGICAL APPROACH TO THE NATURE OF THE AUTOREGULATION OF THE RENAL BLOOD FLOW
}

\author{
Hiroshi OnO, Kiyoshi INAGAKI \\ AND Koroku Hashimoto \\ Department of Pharmacology, Tohoku University \\ School of Medicine, Sendai, Japan
}

The phenomenon that the renal blood flow does not follow the increase in blood pressure but stays almost constant is defined in the renal physiology as the autoregulation of the renal blood flow. Concerning its mechanism, however, very little is yet known, but many theories have been presented.

Meanwhile, the concept of the mediator in the regulation of the peripheral circulation was introduced in the physiology of circulation. Recently BERNE ${ }^{1)}$ assumed that adenosine acted as the mediator in the coronary circulation. This supposition has proved to be quite possible from the evidence gained in our laborator $\mathrm{y}^{2)}$. As for the skeletal muscle, however, IMAI et al. $^{3)}$ thought that the regulation of circulation might not be mediated by adenosine because the skeletal muscle tissue contained too little adenosine after a period of ischemia. The analogous data and conclusion were also presented by GERLACH et al. concerning the tissue of kidney ${ }^{4-5}$.

One of the present authors found that dipyridamol decreases the renal blood flow $^{6}$. Further study in this laboratory revealed that the renal vasculature exhibits a distinctly remarkable feature: adenosine and AMP constrict the renal artery instead of dilating it as in the coronary, femoral or mesenteric arteries. Dipyridamol, characterized as the potentiator of the vascular action of adenosine and the adenine nucleotides, exhibits the same type of vascular action with adenosine and AMP. Hence appears the new perspective that this substance can be useful as a tool in analyzing the physiological role of the adenyl compounds in different tissues. A development of the investigation along this line revealed some clue to the understanding of the regulatory mechanism of the renal blood flow with special reference to the effect of adenosine.

Received for publication April 23, 1966

小野 宏, 稲垣喜代司, 橋本虎六 


\section{METHODS}

The majority of experiments for the study of autoregulation of the renal circulation was arranged by the method of THURAU and KRAMER ${ }^{7}$ as illustrated in the diagram (FIG. 1). Cross circulation was combined in some experiments for confirming the results obtained in the single dog preparations. Results obtained in both methods. were essentially the same.

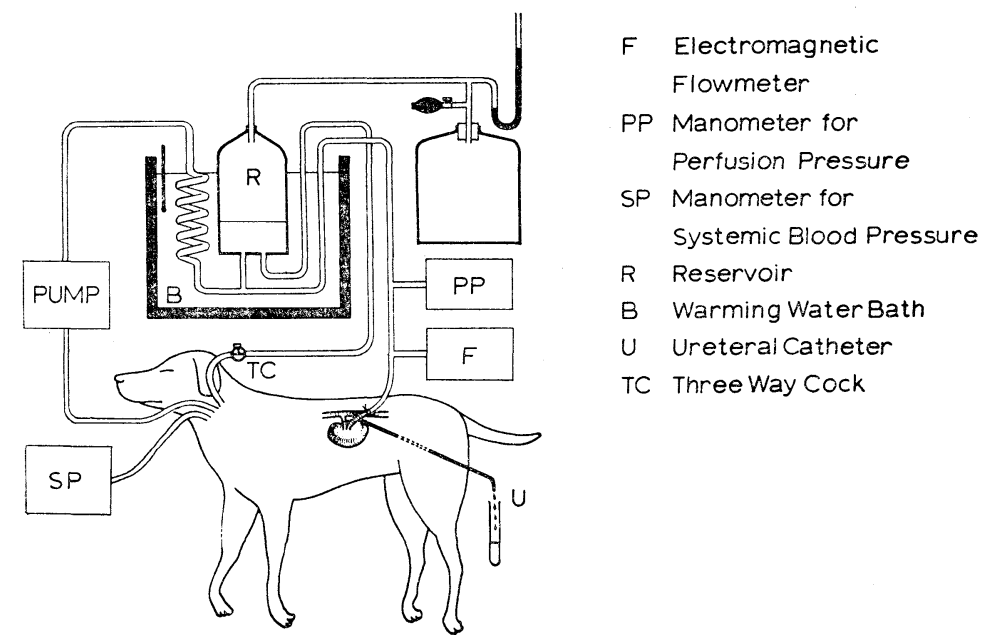

FIG. 1. Diagram of the perfusion system. Carotid arterial blood was brought: into the reservoir glass bottle (R) with a Sigmamotor-pump, where the atmosphere was compressed to a desired pressure level. The blood was perfused into the left renal artery through a polyethylene cannula. Excess blood in the reservoir was. returned to the body by opening the three-way cock (TC). The perfusion pressure was measured with an electric manometer (PP), renal blood flow was measured with an electromagnetic flowmeter (F) and the systemic blood pressure was measured in the carotid artery with another electric manometer (SP); these values were recorded using a pen-writing oscillograph.

Mongrel dogs, both sexes weighing 12 to $20 \mathrm{~kg}$ were used in the experiments. Anesthesia was carried out using morphine $(10 \mathrm{mg} / \mathrm{kg}$. s. c.) and $\alpha$-chloralose $(100 \mathrm{mg} /$ $\mathrm{kg}$. i. v.). Through a wide incision on the left side of the abdomen, the left kidney was exposed retroperitoneally to the origin of the renal artery. The plexus of nerve fibers around the renal artery with adventitial tissue was separated from the vessel. $500 \mathrm{U} / \mathrm{kg}$ of $\omega$-heparin sodium was given intravenously. The left carotid artery was cannulated and the blood led from this artery was driven by Sigmamotor pump into a reservoir glass bottle $(R)$ and then infused into the renal artery through a polyethylene cannula. About $500 \mathrm{ml}$ of heparinized fresh blood was prepared from another dog for filling the perfusion system and the perfusion pressure was adjusted by compressing the atmosphere in the reservoir. The left jugular vein was cannulated and connected to the reservoir in order to return the excess blood by opening a threeway cock (TC), through which the intravenous administration of drugs or the blood transfusion could be done. Test drugs were administered selectively into the rubber tube closely connected to the renal cannula. During the process the authors took great 
care not to spend more than 2 minutes for cannulation in the renal artery and to adjust the perfusion pressure at $100 \mathrm{~mm} \mathrm{Hg}$.

Pressure changes were made by controlling the atmospheric pressure in the reservoir and the response of the vasculature was observed as flow changes. The changed pressure was maintained for a few minutes until the flow rate was regulated and stabilized to a certain level. In order to observe the pressure-flow rate relation, the perfusion pressure and the blood flow were measured by an electric manometer (Nihon Kohden RP-2) and an electromagnetic flowmeter (Nihon Kohden MF-2) respectively. The carotid arterial pressure was recorded simultaneously by another electric manometer.

The drugs tested in the experiments were: dipyridamol (Persantin), theophylline ethylenediamine, acetylcholine hydrochloride, papaverine hydrochloride and norepinephrine hydrochloride. The stock solutions were freshly diluted with saline.

\section{RESULTS}

1) Control observations: characteristics of the autoregulation. For the purpose of observing the pressure-flow relation, the perfusion pressure was changed from the level between 100 and $120 \mathrm{~mm} \mathrm{Hg}$ up or down to a certain level. One typical record is shown in FIG. 2. When the pressure was raised, the

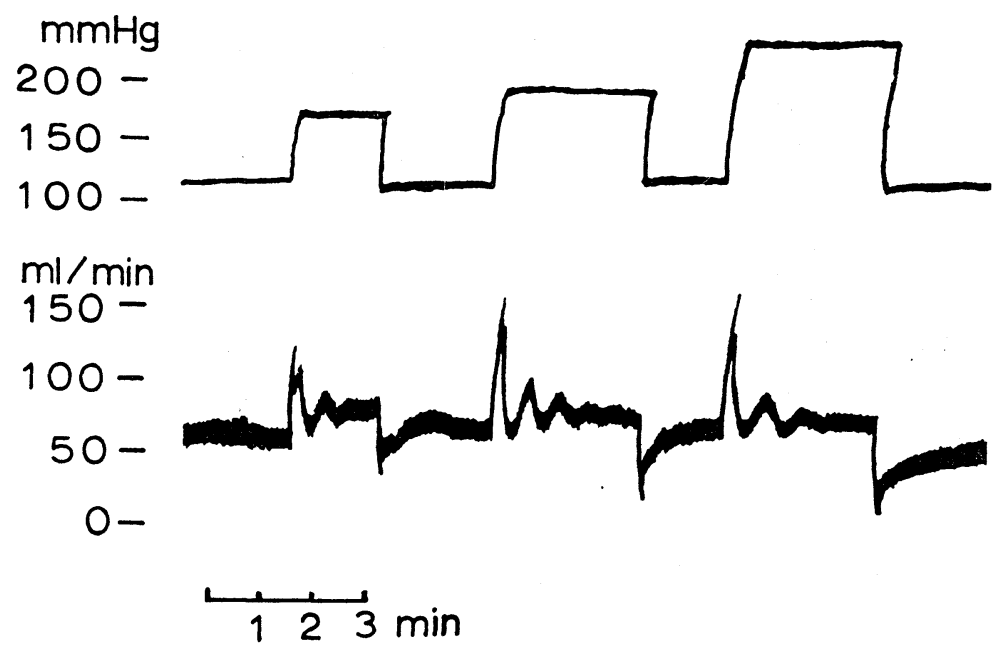

Fig. 2. One of the typical records of the autoregulatory response of the renal blood flow (lower curve) to sudden changes of the perfusion pressure (upper curve).

blood flow increased for a moment but decreased gradually in undulatory fluctuations towards the previous level and converged to a steady level within 1 to 3 minutes. Such oscillation was observed also when the perfusion pressure was lowered. The steady state flow rate and the corresponding perfusion pressure were plotted vis-à-vis to make the pressure-flow curve as shown in FIG. 3. The steady state flow rate was almost constant in the wide range of 


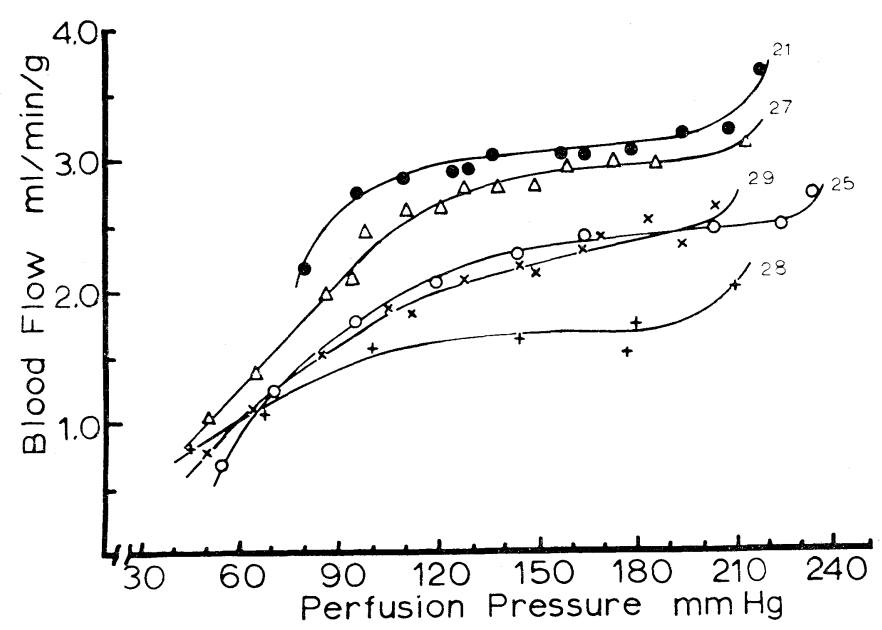

FIG. 3. Autoregulation of the renal blood flow. Pressure-flow curves of control observations. The numerals represent the serial number of experiment.

perfusion pressure from $90 \mathrm{~mm} \mathrm{Hg}$ up to $200 \mathrm{~mm} \mathrm{Hg}$, which proved the autoregulation of the renal circulation.

2) The spontaneous failure of the autoregulation. In the progress of the renal perfusion the autoregulatory mechanism diminished spontaneously (FIG. 5a). In some cases the failure of the autoregulation developed evidently while the systemic hypotension was observed, but in other cases such failure developed without any change in the systemic pressure.

3) Effects of papaverine, theophylline and acetylcholine. Papaverine was infused continuously at the rate of $20 \mathrm{mg} / \mathrm{min}$ into the renal artery. The autoregulation was abolished while the renal blood flow increased markedly as THURAU and KRAMER observed ${ }^{8}$. The infusion of theophylline ethylenediamine at the rate of $5 \mathrm{mg} / \mathrm{min}$ caused a vasodilation and abolished the autoregulatory response. The infusion of acetylcholine at the rate of $0.1 \mathrm{mg} / \mathrm{min}$ resulted in a marked vasodilation and a failure of the autoregulation as NAHMOD and LANARI reported previously ${ }^{11}$. These results are summarized in FIG. 4.

4) Effects of dipyridamol (Persantin) and adenosine on the diminished state of autoregulation. Dipyridamol constricted the renal artery, while adenosine had the same effect and dipyridamol potentiated the effect of adenosine ${ }^{6)}$. The most remarkable fact observed in this experiment was that, when dipyridamol was administered in the diminished state of the autoregulatory response, this drug could restore the deprived autoregulation. Some typical results are shown in FIG. 5a and b. When the renal blood flow was subject to the perfusion pressure (FIG. 5, a), $0.01 \%$ of dipyridamol solution was infused 


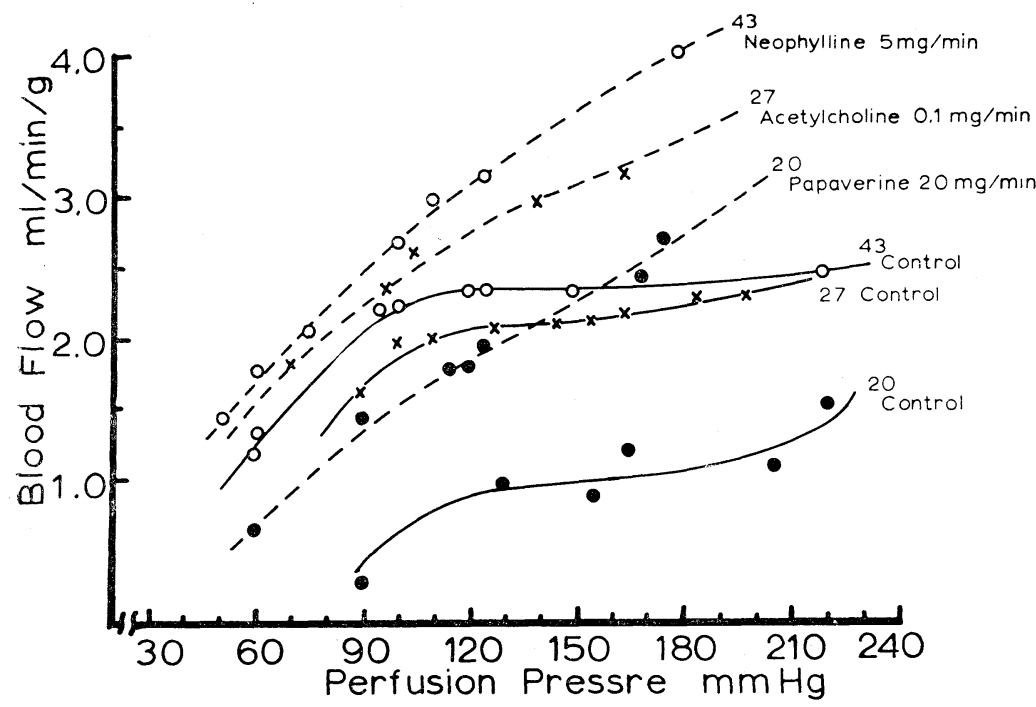

Fig. 4. Abolition of the autoregulation of the renal blood flow by infusions of papaverine $(20 \mathrm{mg} / \mathrm{min})$, Neophylline (preparation of theophylline-ethylendiamine) $(5 \mathrm{mg} / \mathrm{min})$ and acetylcholine $(0.1 \mathrm{mg} / \mathrm{min})$ into the kidney. The numerals represent the serial number of experiments.

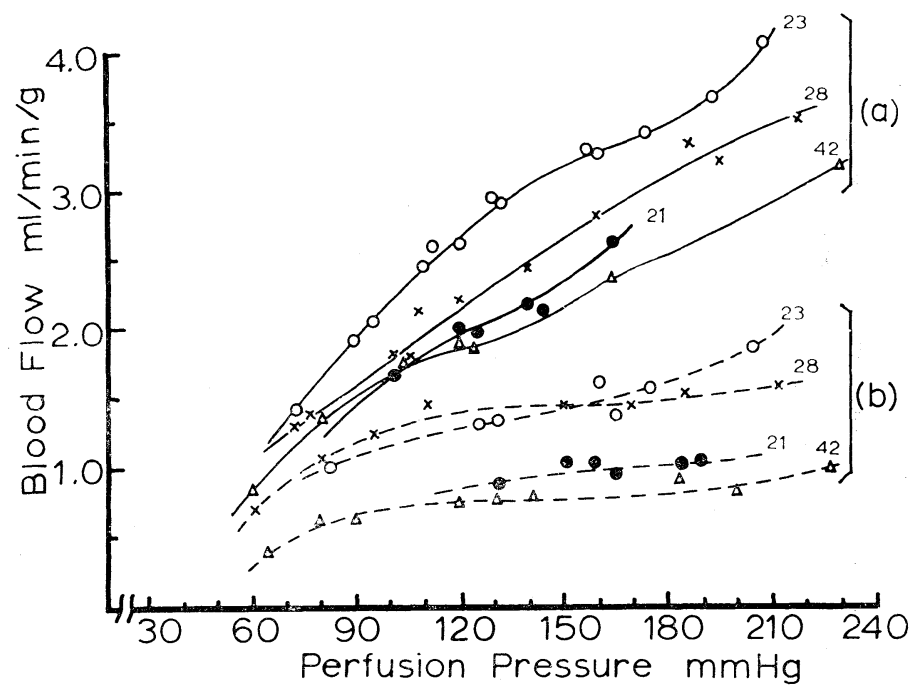

FIG. 5. Spontaneous failure of autoregulation (a) and their restoration through the infusion of dipyridamol $(0.1 \mathrm{mg} / \mathrm{min})$ (b). The numerals represent the serial number of experiments. 


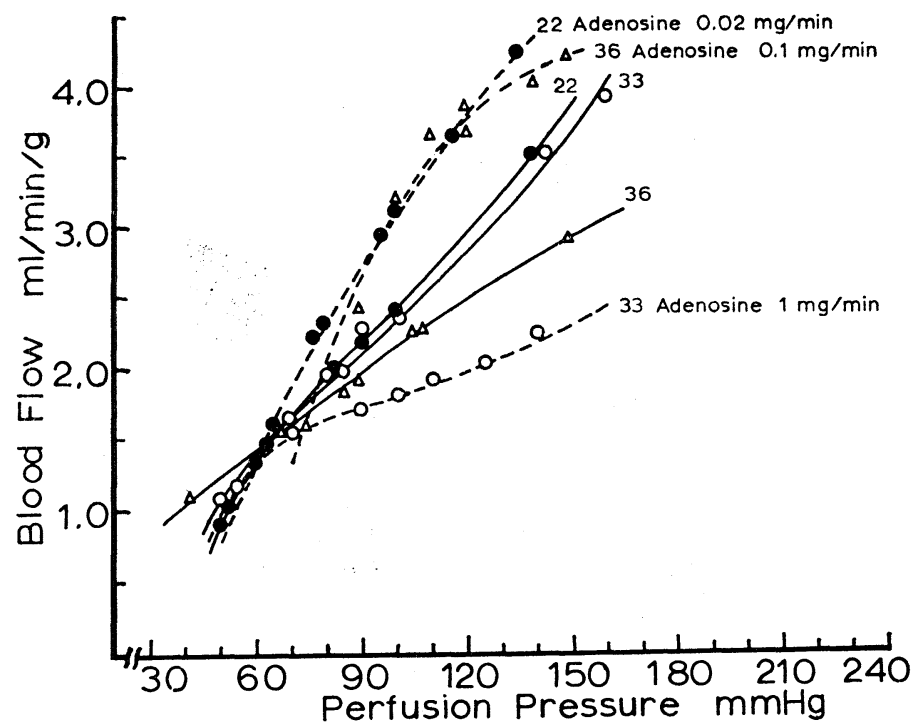

FIG. 6. Effects of the infusion of adenosine in various doses on the spontaneous failure of the autoregulation. Note the ineffectiveness of adenosine to restore the deprived autoregulation of renal blood flow. The numerals represent the serial number of experiments.

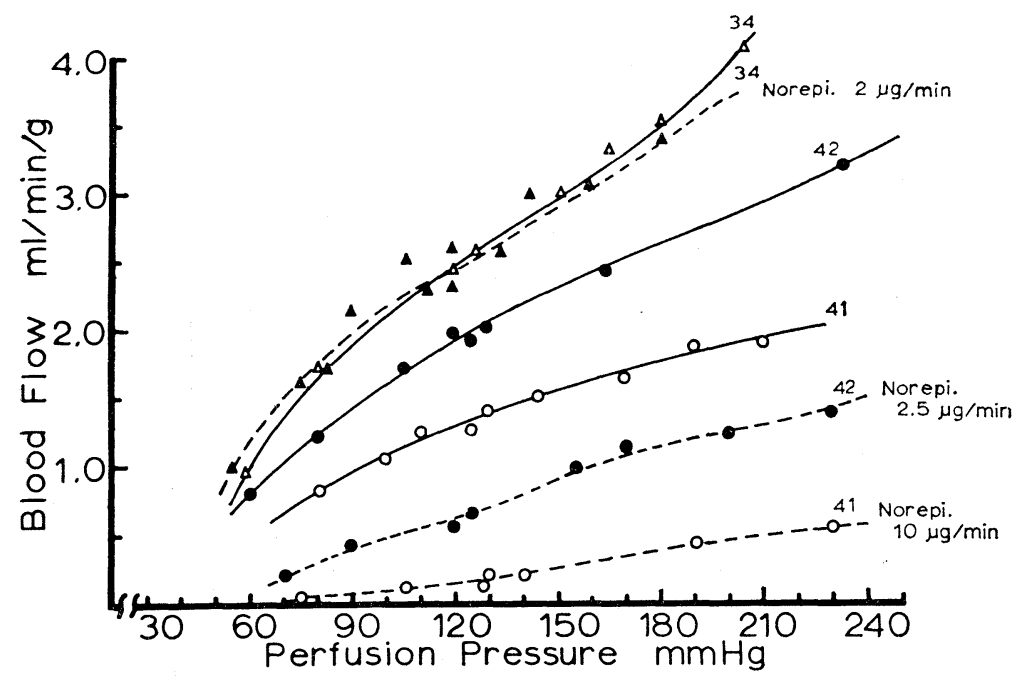

FIG. 7. Ineffectiveness of norepinephrine on the spontanous failure of autoregulation. The numerals at the end of each curve represent the serial number of experiments. 
directly to the kidney at the rate of 0.1 to $0.2 \mathrm{mg} / \mathrm{min}$. The renal blood flow was reduced and stabilized at a certain level. In this stage the kidney showed a better performance of the autoregulation (FIG. 5, b). This effect of dipyridamol lasted for 5 to $15 \mathrm{~min}$. even after the infusion was interrupted. On the other hand adenosine 0.02 to $0.1 \mathrm{mg} / \mathrm{min}$, the dose level which was considered reasonable from the previous report ${ }^{9)}$ did not restore the deprived autoregulation, even though a very large dose might restore it (FIG. 6).

5) Effect of norepinephrine. Norepinephrine was infused into the renal artery. It constricted the renal vasculature, and resulted in the diminution of the blood flow. On the diminished flow level, however, the fluctuation of blood flow was subjected to the perfusion pressure rather than to the autoregulation. In the state of the spontaneous failure of autoregulation, norepinephrine produced a marked vasoconstriction but no recovery of the autoregulation was observed (FIG. 7).

Other vasoconstrictors tested such as vasopressin and tetraethylammonium also failed to restore the autoregulation.

\section{DISCUSSION}

The autoregulatory mechanism is widely accepted as one of the physiological characteristics of the renal circulation, though there is an objection to this ${ }^{10)}$. In regards to this objection it is necessary to point out here that there were some drawbacks in setting up this kind of preparation, i. e., indispensable minimum surgical injuries on the nerve plexus around the renal artery, the temporal induction of the renal ischemia during the procedure of cannulation and the sudden changes of the perfusion pressure, when the renal circulation was either occluded or opened again. As a matter of fact, the urine formation was often less in the perfused kidney and the authors' experiments were carried out under these unavoidable limitations.

The autoregulation in the renal circulation was simply defined as the maintenance of the constancy of the renal blood flow regardless of the wide variation in the blood pressure. This circulatory feature was easily affected. In the process of the renal perfusion or in the administration of some vasoactive substances, the kidney fails to regulate its circulatory volume against the change of blood pressure. It is obvious that there are some similarities and some dissimilarities in the relations between causal agents. In the spontaneous failure, some homeostatic or metabolic disturbance may affect the regulatory mechanism. The infusion experiment with papaverine shows that the autoregulatory mechanism ceases to work when the vascular smooth muscle is completely paralyzed. Theophylline is one of the unspecific vascular smooth muscle relaxants and it almost deprives the muscle of its autoregula- 
tion. Furthermore acetylcholine was reported to be active in stopping the autoregulatory mechanism ${ }^{11}$, although acetylcholine is not a simple vascular smooth muscle relaxant but a stimulant of the vasodilator receptor and sometimes a releaser of catecholamines ${ }^{12)}$. Acetylcholine stimulates the sympathetic neuron, and given in large doses it causes vasoconstriction of the kidney blood vessels ${ }^{13)}$. Recently noradrenaline was reported by FoLKOw and LANGSTON $^{14)}$, and DE WARDENER et al. ${ }^{15)}$ to affect the autoregulation of the renal blood flow. The authors have also had such results, even though the autoregulatory mechanism is not easy to observe during very strong constriction of the renal artery. The complete relaxation by use of papaverine and theophylline looked to be potent evidence for the myogenic theory of the renal autoregulation, but it is rather difficult to find an adequate explanation for the deprivation of renal autoregulation by infusion of acetylcholine and epinephrine. FOLKOW and LANGSTON tried to explain the actual cause of the spontaneous failure of renal autoregulation as the sequence of vasomotor activity, but the authors do not completely agree with them, for the data connecting the spontaneous failure with vasomotor activity is lacking. In conclusion, the mechanism of the renal autoregulation and also the causes of loss of regulation are not easily understood at present, but the authors suspect the existence of an unknown local intrinsic degradation of the mechanism of autoregulation.

Here, a specific action of dipyridamol to restore the deprived autoregulation of the renal blood flow is worthy of special note, because there has been no report on drugs of such activity and dipyridamol is by no means an adrenolytic agent. Dipyridamol has been introduced as a coronary vasodilator. Let us refer, then, to the hypothesis of BERNE et al. that adenosine may play the role of mediator in the metabolic regulation of the coronary blood flow, and then the action of dipyridamol for the coronary circulation is quite understandable. Turning to the reaction in the renal circulation, AMP, adenosine, DPN and dipyridamol induce renal vasoconstriction, but dipyridamol dose so through potentiating the effects of adenine nucleotides and adenosine ${ }^{6)}$. Thus, it is more than mere coincidence that dipyridamol as the potentiator of adenine compounds has a favorable effect on the autoregulation of the renal blood flow. In comparison with the restorative action of dipyridamol, adenosine infusion is of little effect. This may be because, when extrinsically applied, adenosine is not necessarily effective for restoring the regulatory mechanism as intrinsic adenosine might do. Recent works show, however, that AMP is deaminated to IMP and then to inosine in the renal tissue. IMP and inosine are both ineffective on the renal circulation. Furthermore GER$\mathrm{LACH}$ et al. estimated the amount of nucleotides in the kidney after ischemia and found no adenosine in the renal tissue. Recently THURAU ${ }^{16)}$ stated the hypothesis of the adenine nucleotides activity in the juxtaglomerular cells in 
connection with the renin-angiotensin mechanism for the renal autoregulation. Thus there may be two possible explanations, i.e., either 1) AMP is the mediator in the regulatory mechanism of the renal vessels, or 2) the metabolism of the vascular smooth muscle in such a particular structure as the juxtaglomerular cells is different from that of the substantial renal tissue. The pharmacological feature of dipyridamol on the renal vasoconstriction has nothing to do with its effectiveness in the restoration of deprived autoregulation; therefore, this effect is concerned with the adenine nucleotides metabolism in the vascular smooth muscle in some particular part of the renal artery. Reversely speaking, the spontaneous failure of the renal autoregulation may be due to a malfunctioning in the adenine nucleotide metabolism in some particular site of the renal artery, just as the cause of the spontaneous heart failure in the heart-lung preparation may be considered to lie in the failure of the utilization of high energy adenylic compounds. Dipyridamol has no effect on the drug produced failure of the renal autoregulation.

\section{SUMMARY}

1. The dog's kidney perfused with its own blood showed a good performance of the autoregulation of the blood flow.

2. The autoregulation of the renal blood flow was liable to diminish and disappear spontaneously.

3. The autoregulation was abolished with the infusion of papaverine, theophylline, acetylcholine or norepinephrine.

4. Dipyridamol, infused into the renal artery, restored the autoregulation of the renal blood flow from the deprived state of the spontaneous failure, but not from that induced by drugs. Its significance was discussed in relation to the adenine nucleotide metabolism of the renal blood vessels.

This work was supported by grants of Pharmacological Research Foundation, inc. and Ministry of Education (No. 91043). The authors express thanks to Mrs. K. YosHio for typewriting this manuscript.

\section{REFERENCES}

1) Berne, R.M.: Cardiac nucleotides in hypoxia: Possible role in regulation of coronary blood flow. Am. J. Physiol. $204:$ 317, 1963.

2) Miura, M., Tominaga, S. and Hashimoto, K.: Potentiation of reactive hyperemia by selective use of dipyridamol in the coronary and femoral circulation. to. be published Arzneimittel Forsch.

3) Imai, S., Riley, A. L. ANd Berne, R.M.: Effect of ischemia on adenine nucleotides in cardiac and skeletal muscle. Circulation Res. 15: 443, 1964.

4) Gerlach, E., Deuticke, B. und Dreisbach, R. H.: Zum Verhalten von Nucleotiden und ihren dephosphorylierten Abbauprodukten in der Niere bei Ischämie 
und kurzzeitiger post-ischämischer Wiederdurchblutung. Pflügers Archiv 278 : 296, 1963.

5) Gerlach, E., Deuticke, B. und Dreisbach, R. H.: Stoffwechsel von Adeninnucleotiden in Nierenschnitten unter verschiedenen experimentellen Bedingungen und während post-anoxischer Erholung. Pflügers Archiv 284 : 213, 1965.

6) Hashimoto, K., Kumakura, S. and Tanemura, I.: Mode of action of adenine, uridine, and cytidine nucleotides and 2,6-bis (diethanolamino)-4,8-dipiperidinopyrimidino (5, 4-d) pyrimidine on the coronary, renal and femoral arteries. Arzneimittelforsch. $14: 1252,1964$.

7) Thurau, K. und Kramer, K.: Die Reaktionsweise der glatten Muskulatur der Nierengefässe auf Dehnungsreize und ihre Bedeutung für die Autoregulation des Nierenkreislaufes. Pflügers Archiv 268 : 188, 1958.

8) Thurau, K. und Kramer, K.: Weitere Untersuchungen zur myogenen Natur der Autoregulation des Nierenkreislaufes. Pfïgers Archiv 269: 77, 1959.

9) Hashimoto, K. and Kumakura, S.: The pharmacological features of the coronary, renal, mesenteric and femoral arteries. Jap. J. Physiol. 15: 540, 1965.

10) Langston J.B., Guyton, C. And Gillespie, W. J. Jr.: Acute effect of changes in renal arterial pressure and sympathetic blockade on kidney function. Am. J. Physiol. $197:$ 595, 1959.

11) Nahmod, V.E. AND LANARI, A.: Abolition of autoregulation of renal blood flow by acetylcholine. Am. J. Physiol. $207:$ 123, 1964.

12) Burn, J. H. And Rand, M. J.: Sympathetic postganglionic cholinergic fibers. Brit. J. Pharmacol. $15: 56,1960$.

13) Åström, A., Grafoord, J. And SAmelius-Broberg, U.: Vasoconstrictor action of acetylcholine on kidney blood vessels. Acta physiol. scand. 61: 159, 1964.

14) Folkow, B. ANd Langston, J.: The interrelationship of some factors influencing renal blood flow autoregulation. Acta physiol. scand. 61: 165, 1964.

15) DeWardener, H. E. And Miles, B. E.: The effect of haemorrhage on the circulatory autoregulation of the dog's kidney perfused in situ. Clin. Sci. $11: 267,1952$.

16) Thurau K.: Renal hemodynamics. Am.J. Med. 36: 698, 1964. 